Kazuo Yamamoto • Yoko Soeda • Toshinori Kamisako

Hiroo Hosaka • Miya Fukano • Hiroshi Sato

Yoshihide Fujiyama · Yukihiko Adachi · Yuzuru Satoh

Tadao Bamba

\title{
Analysis of bilirubin uridine 5'-diphosphate (UDP)-glucuronosyltransferase gene mutations in seven patients with Crigler-Najjar syndrome type II
}

Received: July 4, 1997 / Accepted: August 25, 1997

\begin{abstract}
Crigler-Najjar syndrome (CN) type II is caused by a reduction in hepatic bilirubin uridine $5^{\prime}$-diphosphate (UDP)-glucuronosyltransferase activity. Recently, there has been progress in mutation analysis of patients with $\mathrm{CN}$ type II. Here, we analyzed both the coding and the promoter regions of the gene in seven Japanese patients with $\mathrm{CN}$ type II from five unrelated families. The mutations found in this study were classified into three types. The first type was composed of double homozygous missense mutations (Gly71Arg and Tyr486Asp) in exons 1 and 5. These mutations, which were detected in five patients from three unrelated families, were the commonest. The second type, which was detected in one patient, consisted of a single homozygous missense mutation (Arg209Trp) in exon 1. The third type, which was detected in one patient and was a new type of mutation combination, was composed of a homozygous insertion mutation of the TATAA element and a heterozygous missense mutation (Pro229Gln) in exon 1. Although the first and the second type of mutations are recessive, the third type appears to be dominant with
\end{abstract}

\section{H. Sato $(\bowtie)$}

Department of Biology, Shiga University of Medical Science, Seta

Tsukinowa, Otsu, Shiga 520-21, Japan

Tel.: +81-775-48-2121; Fax: +81-775-48-2415

e-mail: satoh@bellebsd.shiga-med.ac.jp

K. Yamamoto $\cdot$ M. Fukano $\cdot$ Y. Fujiyama $\cdot$ T. Bamba

Second Department of Internal Medicine, Shiga University of

Medical Science, Shiga, Japan

Y. Soeda $\cdot$ Y. Satoh

Department of Obstetrics and Gynecology, Meiji College of Oriental Medicine, Kyoto, Japan

T. Kamisako

Second Department of Internal Medicine, Kinki University School of Medicine, Osaka, Japan

H. Hosaka

Internal Medicine, Saiseikai-Yokohama-City-Nanbu Hospital,

Yokohama, Kanagawa, Japan

Y. Adachi

Third Department of Internal Medicine, Mie University School of

Medicine, Tsu, Japan incomplete penetrance, since the allele frequency of the insertion mutation of the TATAA element is very high $(40 \%)$.

Key words Crigler-Najjar syndrome type II - Mutation · Inheritance

\section{Introduction}

Crigler-Najjar syndrome (CN) type II, which was first described by Arias et al., is characterized by chronic nonhemolytic unconjugated hyperbilirubinemia (Arias 1962). The jaundice in a patient with CN type II is caused by a reduction in hepatic bilirubin uridine $5^{\prime}$-diphosphate (UDP)-glucuronosyltransferase (B-UGT) activity (to less than $10 \%$ of normal). Recently, the $U G T 1 * 1$ gene which encodes the enzyme was identified (Ritter et al. 1992), and there has been progress in mutation analysis of CN type I, $\mathrm{CN}$ type II, and Gilbert's syndrome.

In recent studies on mutation analysis of patients with $\mathrm{CN}$ type II, five types of mutations which exist exclusively in the coding region have been reported: a single homozygous missense mutation (Arg209Trp) (Bosma et al. 1993), a single homozygous missense mutation (Gln331Arg) (Moghrabi et al. 1993), double homozygous missense mutations (Gly71Arg and Tyr486Asp) (Aono et al. 1993), heterozygous missense (Leu175Glu) and frame shift mutations (Seppen et al. 1994), and a single heterozygous nonsense mutation (Gln331Stop) (Koiwai et al. 1996).

On the other hand, it has been revealed that Gilbert's syndrome is caused by both missense mutations in the coding region (Aono et al. 1995) and a homozygous insertion mutation of the TATAA element in the promoter region (Bosma et al. 1995). It is hypothesized that the abnormality of the promoter region would also be one of the contributing factors in $\mathrm{CN}$ type II. To test this hypothesis, we analyzed both the coding and the promoter regions of the gene in seven Japanese patients with CN type II, and discuss the characteristics of their mutations. 


\section{Materials and methods}

Patients and samples

The diagnosis of $\mathrm{CN}$ type II was based on the elevation of serum bilirubin concentration from $60 \mu \mathrm{M}$ to $340 \mu \mathrm{M}$, with no evidence of hemolytic jaundice or other liver disease. Patient 1 was a 19-year-old male; his serum bilirubin concentration was $86 \mu \mathrm{M}$. Patients 2,3 , and 4 were sisters. Their ages were 58,60 , and 74 years old, respectively. Their serum bilirubin concentrations were 332,154 , and $282 \mu \mathrm{M}$, respectively. Patient 5 was a 53 -year-old female with a serum bilirubin concentration of $238 \mu \mathrm{M}$. Patient 6 was a 74 -yearold male; his serum bilirubin concentration was $258 \mu \mathrm{M}$. Patient 7 was a 51-year-old male with a serum bilirubin concentration of $333 \mu \mathrm{M}$. Bile analysis revealed $75.6 \%$ of bilirubin monoglucuronide and $5.3 \%$ of bilirubin diglucuronide. A liver biopsy specimen revealed no liver disease. Phenobarbital treatment reduced serum bilirubin concentration to $91 \mu \mathrm{M}$.

Two pairs of parents, those of patients $2-4$ and 5, were consanguineous. It was unclear whether or not the parents of patient 1,6 , and 7 were consanguineous.

Polymerase chain reaction (PCR) and DNA sequencing

Genomic DNA was extracted from white blood cells. The promoter and coding regions of the $U G T 1 * 1$ gene were amplified as described elsewhere (Aono et al. 1994; Soeda et al. 1995). Sense and anti-sense primers used for PCR to amplify the TATAA element of the gene were 5'-GCCATATATATATATATA-3' and 5'-GCTTGCTCAGCATATATCTGGG-3'. Direct sequencing was performed three times for each patient as previously described (Aono et al. 1994).

\section{Results}

Patient 1 was heterozygous for a $\mathrm{C}$ to $\mathrm{A}$ transversion at codon 229 (position 686) in exon 1 (Fig. 1, Table 1). This nucleotide shift resulted in a substitution of glutamine for proline. He was also homozygous for an insertion mutation of the TATAA element (which contained two extra nucleotides (TA), a "long TATAA element") in the promoter region (Bosma et al. 1995).

Patient 2 was homozygous for a $\mathrm{G}$ to $\mathrm{A}$ transition at codon 71 (position 211) in exon 1 (Fig. 2A) and homozygous for a $T$ to $G$ transversion at codon 486 (position 1456) in exon 5 (Fig. 2B). The first mutation resulted in a substitu-

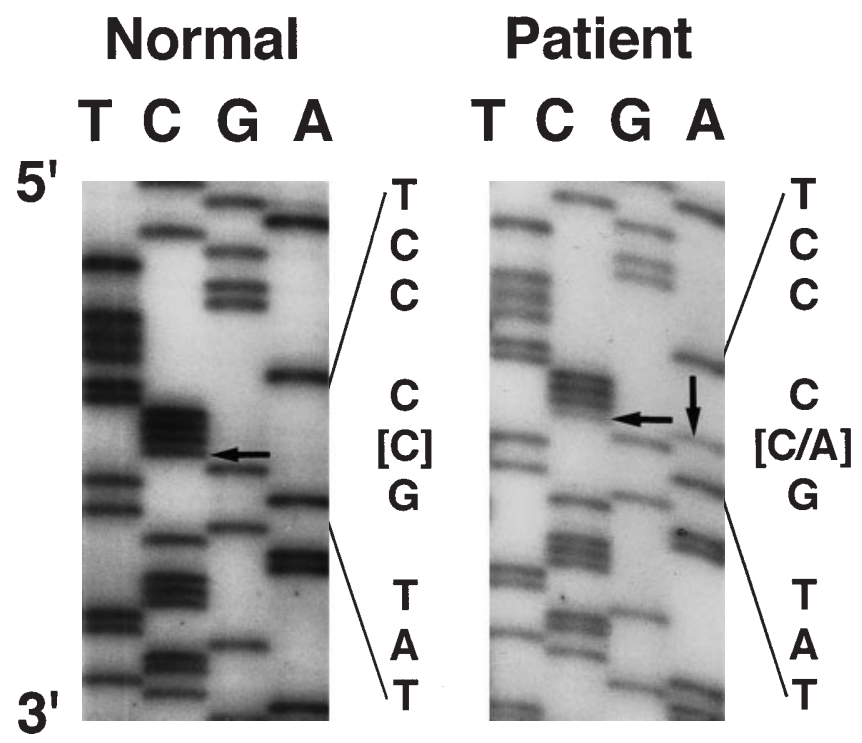

Fig. 1 Nucleotide sequence of region around position 686 of the $U G T 1 * 1$ gene from a normal control and patient 1 . A heterozygous $\mathrm{C}$ to A transversion at position 686 is shown

Table 1 Clinical features and mutations

\begin{tabular}{|c|c|c|c|c|c|c|}
\hline $\begin{array}{l}\text { Patient } \\
\text { number }\end{array}$ & Sex & Age & $\begin{array}{l}\text { Bilirubin } \\
(\mu \mathrm{M})\end{array}$ & $\begin{array}{l}\text { TATAA element } \\
\text { (zygosity) }\end{array}$ & $\begin{array}{l}\text { Mutations in the coding } \\
\text { region (zygosity) }\end{array}$ & Exon \\
\hline 1 & M & 19 & 86 & $\begin{array}{l}\text { Long }{ }^{\mathrm{a}} \\
\text { (homo) }\end{array}$ & Pro229Gln (hetero) & 1 \\
\hline 2 & $\mathrm{~F}$ & 58 & 332 & $\begin{array}{l}\text { Normal }^{b} \\
\text { (homo) }\end{array}$ & $\begin{array}{l}\text { Gly71Arg (homo) } \\
\text { Tyr486Asp (homo) }\end{array}$ & $\begin{array}{l}1 \\
5\end{array}$ \\
\hline 3 & $\mathrm{~F}$ & 60 & 154 & $\begin{array}{l}\text { Normal } \\
\text { (homo) }\end{array}$ & $\begin{array}{l}\text { Gly71Arg (homo) } \\
\text { Tyr486Asp (homo) }\end{array}$ & $\begin{array}{l}1 \\
5\end{array}$ \\
\hline 4 & $\mathrm{~F}$ & 74 & 282 & $\begin{array}{l}\text { Normal } \\
\text { (homo) }\end{array}$ & $\begin{array}{l}\text { Gly71Arg (homo) } \\
\text { Tyr486Asp (homo) }\end{array}$ & $\begin{array}{l}1 \\
5\end{array}$ \\
\hline 5 & $\mathrm{~F}$ & 53 & 238 & $\begin{array}{l}\text { Normal } \\
\text { (homo) }\end{array}$ & $\begin{array}{l}\text { Gly71Arg (homo) } \\
\text { Tyr486Asp (homo) }\end{array}$ & $\begin{array}{l}1 \\
5\end{array}$ \\
\hline 6 & M & 74 & 258 & $\begin{array}{l}\text { Normal } \\
\text { (homo) }\end{array}$ & $\begin{array}{l}\text { Gly71Arg (homo) } \\
\text { Tyr486Asp (homo) }\end{array}$ & $\begin{array}{l}1 \\
5\end{array}$ \\
\hline 7 & M & 51 & 333 & $\begin{array}{l}\text { Normal } \\
\text { (homo) }\end{array}$ & Arg209Trp (homo) & 1 \\
\hline
\end{tabular}

\footnotetext{
${ }^{a}$ Long, a long TATAA element caused by insertion mutation: ATATATATATATATATAA.
}

${ }^{\mathrm{b}}$ Normal, indicates a normal TATAA element: ATATATATATATATAA. 


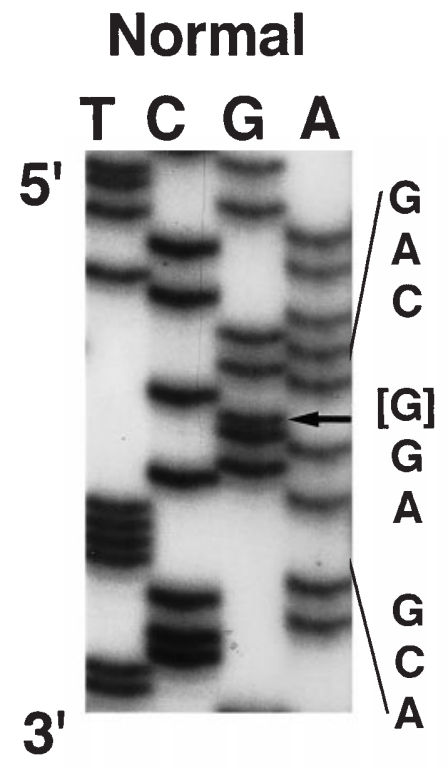

Patient
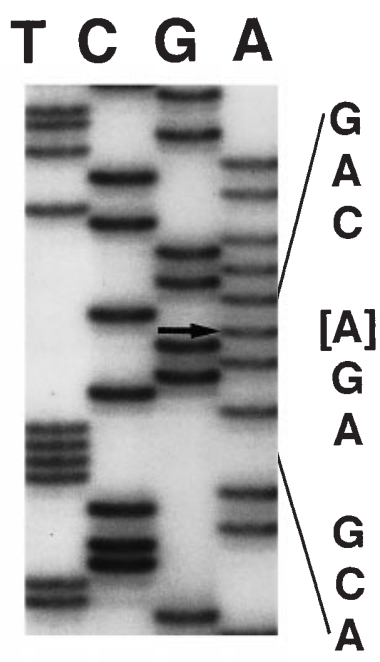

(A)

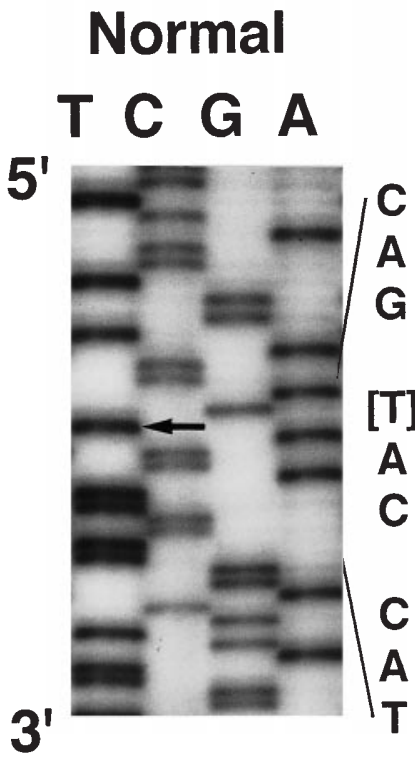

\section{Patient}
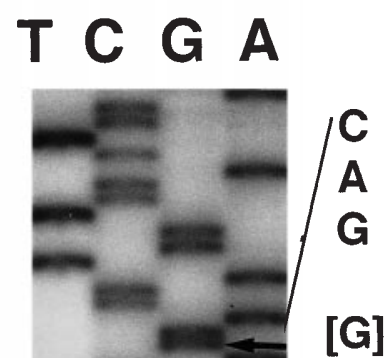

A

C

C
A
$T$

(B)

Fig. 2 A Nucleotide sequence of region around position 211 of the $U G T 1 * 1$ gene from a normal control and patient 2 . A homozygous $\mathrm{G}$ to A transition at position 211 is shown. B Nucleotide sequence of region around position 1456 of the $U G T 1 * 1$ gene from a normal control and patient 2. A homozygous $\mathrm{T}$ to $\mathrm{G}$ transversion at position 1456 is shown

tion of arginine for glycine, and the second mutation resulted in a substitution of aspartate for tyrosine. He was homozygous for a normal TATAA element. Patients 3-6 had mutations which were identical to those of patient 2 .

Patient 7 was homozygous for a $\mathrm{C}$ to $\mathrm{T}$ transition at codon 209 (position 625) in exon 1 (Fig. 3), resulting in a substitution of tryptophan for arginine. He was homozygous for a normal TATAA element.
Normal

Patient

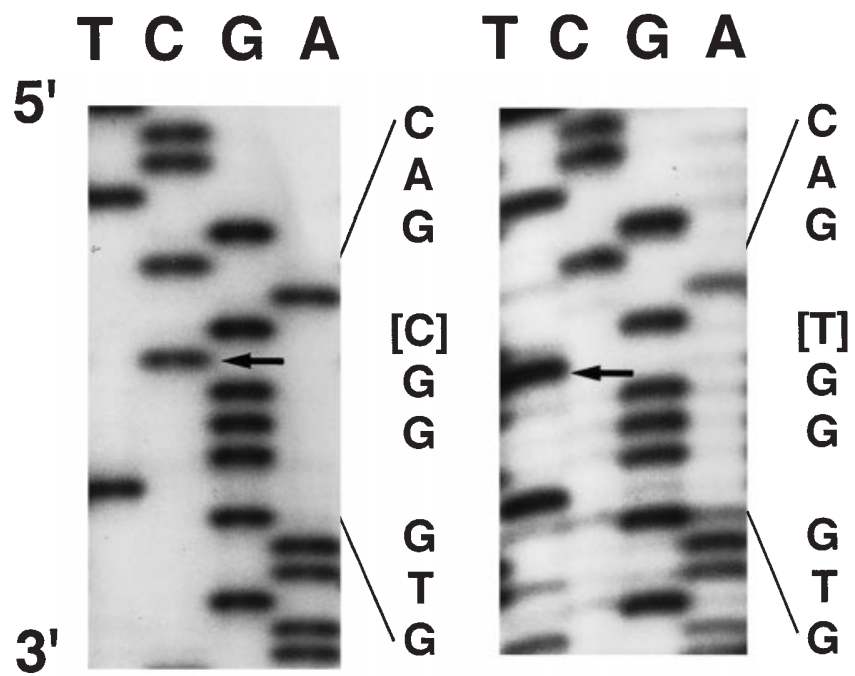

Fig. 3 Nucleotide sequence of region around position 625 of the $U G T 1^{*} 1$ gene from a normal control and patient 7 . A homozygous $\mathrm{C}$ to $\mathrm{T}$ transition at position 625 is shown

The ages of the patients, and their mutations and serum bilirubin concentrations, are summarized in Table 1 . The serum bilirubin concentrations of patients $2-6$, who had identical double homozygous mutations, were at almost the same level. The serum bilirubin concentration of patient 1 , who had a homozygous long TATAA element and heterozygous missense mutation, was the lowest of the seven. Every patient had mutations in exon 1, which encodes the $\mathrm{N}$-terminal half of the B-UGT.

\section{Discussion}

Following identification of the $U G T 1^{*} 1$ gene (Ritter et al. 1992), there has been progress in mutation analysis of patients with $\mathrm{CN}$ type II. Until now, five types of mutations which exist exclusively in the coding region have been reported, as described earlier.

In this study, an additional, new type of mutation combination was found in patient 1 . Gene analysis of patient 1 showed that he had both a homozygous insertion mutation of the TATAA element and a heterozygous missense mutation (Pro229Gln) in exon 1. Recently, we reported two patients with Gilbert's syndrome who were heterozygous for the same missense mutation (Pro229Gln), and the mutated enzyme had $25 \%$ of normal activity in the heterozygous state based on an in vitro expression study (Koiwai et al. 1995). Furthermore, the insertion mutation of the TATAA element was reported to reduce the transcriptional level of the gene to about $30 \%$ of normal in the homozygous state during in vitro expression experiments (Bosma et al. 1995). However, the reduction of activity caused by each mutation was not sufficient to express the phenotype of $\mathrm{CN}$ type II, because the enzyme activity of a 
patient with $\mathrm{CN}$ type II is generally less than $10 \%$ of normal. Therefore, the phenotype as $\mathrm{CN}$ type II of this patient would appear to be caused by a combination of the heterozygous missense and homozygous insertion mutations.

Double homozygous missense mutations (Gly71Arg and Tyr486Asp) in different exons were detected in patients 2 6 . These mutations were identical to those found in another patient reported earlier (Aono et al. 1993). We could not clearly indicate which mutation contributed to the phenotype as CN type II in the previous report. However, following that study, we found a patient with Gilbert's syndrome who was a single homozygote for Gly71Arg (Soeda et al. 1995). Furthermore, double homozygotes for Gly71Arg and Tyr486Asp always express the phenotype of CN type II, so both of these homozygous missense mutations would additionally contribute to elevation of serum bilirubin concentration to the level found in $\mathrm{CN}$ type II. A total of six patients with $\mathrm{CN}$ type II who had these double homozygous mutations, from four unrelated families, were detected, including one case reported by Aono et al. (1993) These mutations were the commonest of those encountered in our study of Japanese patients. Patients 2-4 (they were sisters) and patient 6 resided in Kanagawa prefecture. Patient 5 and the patient reported by Aono et al. (1993) resided in Kyoto and Aichi prefectures, respectively. An obvious concentration of the patients with the double mutation could not be demonstrated in a specific local area.

In patient 7 , a single homozygous missense mutation (Arg209Trp) was found in exon 1. This mutation was identical to one reported earlier (Bosma et al. 1993). The serum bilirubin concentration of patient $7(333 \mu \mathrm{M})$ was comparable to that of the previously reported case $(340 \mu \mathrm{M})$. This mutation is the first of its type in a Japanese patient with $\mathrm{CN}$ type II.

Based on pedigree analysis, the inheritance of $\mathrm{CN}$ type II has been postulated to be autosomal recessive (Blaschke et al. 1974; Hunter et al. 1973) or autosomal dominant with incomplete penetrance (Arias et al. 1969). Gene analyses have shown both patients having recessive traits with homozygous missense mutations and a patient having dominant traits with a heterozygous nonsense mutation (Aono et al. 1993; Bosma et al. 1993; Koiwai et al. 1996). In our study, inheritance in patients 2-7 was recessive, in agreement with findings reported earlier; however, patient 1 appears to show complicated inheritance. We could not analyze the pedigree of patient 1 , but it is speculated that the apparent inheritance of the patient would be detected as autosomal dominant with incomplete penetrance because the allele frequency of the insertion mutation of TATAA element is very high (40\%; Bosma et al. 1995).

Acknowledgments We are indebted to Professor Y. Doida (Shiga University of Medical Science) for encouragement and advice in our study and to Mr. R. Okamoto and Mr. M. Suzaki of the Central Research Laboratory for their technical help. We would like to thank Dr. T.
Sakonjyu (Kanagawa National Hospital), Professor Y. Hukuda (Kyoto University), Dr. K. Okuma, Dr. Y. Okumura, Dr. M. Nagano (Kyushu Kouseinenkin Hospital), and Dr. R. Niimi (National Children's Hospital) for providing DNA samples from patients with CN type II. This work was supported in part by grants-in-aid for scientific research from the Ministry of Education, Science, and Culture of Japan (08557030 and 08670878).

\section{References}

Aono S, Yamada Y, Keino H, Hanada N, Nakagawa T, Sasaoka Y, Yazawa T, Sato H, Koiwai O (1993) Identification of defect in the genes for bilirubin UDP-glucuronosyltransferase in a patient with Crigler-Najjar syndrome type II. Biochem Biophys Res Commun 197: 1239-1244

Aono S, Yamada Y, Keino H, Sasaoka Y, Nakagawa T, Onishi S, Mimura S, Koiwai O, Sato H (1994) A new type of defect in the gene for bilirubin uridine $5^{\prime}$-diphosphate-glucuronosyltransferase in a patient with Crigler-Najjar syndrome type I. Pediatr Res 35: 629-632

Aono S, Adachi Y, Uyama E, Yamada Y, Keino H, Nanno T, Koiwai $\mathrm{O}$, Sato $\mathrm{H}$ (1995) Analysis of genes for bilirubin UDPglucuronosyltransferase in Gilbert's syndrome. Lancet 345: 958-959

Arias IM (1962) Chronic unconjugated hyperbilirubinemia without overt signs of hemolysis in adolescents and adults. J Clin Invest 41: 2233-2245

Arias IM, Gartner LM, Cohen M, Ezzer JB, Levi AJ (1969) Chronic nonhemolytic unconjugated hyperbilirubinemia with glucuronyl transferase deficiency. Am J Med 47: 395-409

Blaschke TF, Berk PD, Rodkey FL, Scharschmidt BF, Collison HA, Waggoner JG (1974) Effects of glutethimide and phenobarbital on hepatic bilirubin clearance, plasma bilirubin turnover, and carbon monoxide production in man. Biochem Pharmacol 23: 2795-2806

Bosma PJ, Goldhoorn B, Oude Elferink RPJ, Sinaasappel M, Oostra BA, Jansen PLM (1993) A mutation in bilirubin uridine 5'diphosphate-glucuronosyltransferase isoform 1 causing CriglerNajjar syndrome type II. Gastroenterology 105: 216-220

Bosma PJ, Roy Chowdhury J, Bakker C, Gantla S, de-Boer A, Oostra BA, Lindhout D, Tytgat GNJ, Jansen PLM, Oude Elferink RPJ, Roy Chowdhury N (1995) The genetic basis of the reduced expression of bilirubin UDP-glucuronosyltransferase 1 in Gilbert's syndrome. N Engl J Med 333: 1171-1175

Hunter JO, Thompson RPH, Dunn PM, Williams R (1973) Inheritance of type 2 Crigler-Najjar hyperbilirubinemia. Gut 14: 46-49

Koiwai O, Nishizawa M, Hasada K, Aono S, Adachi Y, Mamiya N, Sato H (1995) Gilbert's syndrome is caused by a heterozygous missense mutation in the gene for bilirubin UDP-glucuronosyltransferase. Hum Mol Genet 4: 1183-1186

Koiwai O, Aono S, Adachi Y, Kamisako T, Yasui Y, Nishizawa M, Sato H. (1996) Crigler-Najjar syndrome type II is inherited both as a dominant and as a recessive trait. Hum Mol Genet 5: 645-647

Moghrabi N, Clarke DJ, Boxer M, Burchell B (1993) Identification of an A-to-G missense mutation in exon 2 of the UGT1 gene complex that causes Crigler-Najjar syndrome type 2. Genomics 18: 171-173

Ritter JK, Chen F, Sheen YY, Tran HM, Kimura S, Yeatman MT, Owens IS (1992) A novel complex locus UGT1 encodes human bilirubin, phenol, and other UDP-glucuronosyltransferase isozymes with identical carboxyl termini. J Biol Chem 267: 3257-3261

Seppen J, Bosma PJ, Goldhoorn BG, Bakker CTM, Roy Chowdhury J, Roy Chowdhury N, Jansen PLM, Oude Elferink RPJ (1994) Discrimination between Crigler-Najjar type I and II by expression of mutant bilirubin uridine diphosphate-glucuronosyltransferase. J Clin Invest 94: 2385-2391

Soeda Y, Yamamoto K, Adachi Y, Hori T, Aono S, Koiwai O, Sato H (1995) Predicted homozygous mis-sense mutation in Gilbert's syndrome. Lancet 346: 1494 